\title{
25 \\ Language in the Mainland Southeast Asia Area
}

N. J. Enfield

\subsection{Mainland Southeast Asia and its People}

Mainland Southeast Asia (hereafter MSEA) can be broadly defined as the area occupied by present day Cambodia, Laos, Peninsular Malaysia, Thailand, Myanmar and Vietnam, along with areas of China south of the Yangzi River. Also sometimes included are the seven states of Northeast India, and - although here the term 'mainland' no longer applies - the islands from Indonesia and Malaysia running southeast to Australia and West Papua (see Map 25.1).

There are no exact borders around the MSEA area. Different scholars draw lines in different places. But there is nevertheless a core (Comrie 2007: 45). MSEA is always taken to include Indochina - Vietnam, Laos and Cambodia - together with Thailand, and usually Peninsular Malaysia and part or all of Myanmar (see Map 25.2). But there is often a broader scope of Greater MSEA, moving beyond the core area of Indochina and Thailand, in all directions; for recent work, see Vittrant (2015) and Jenny and Sidwell (2015) on Myanmar (cf. Bradley 1995; Watkins 2005), Post (2015) on Northeast India (cf. Hyslop, Morey and Post 2011, 2012, 2013; Morey and Post 2008, 2010), Gil (2015) on Insular Southeast Asia (cf. Adelaar and Himmelmann 2005; Blust 2013a, 2013b), and de Sousa (2015) on southern China (cf. Ansaldo and Matthews 2001; Bauer 1996; Chappell 2001).

MSEA is a tropical and sub-tropical area with rugged and well-forested hills and river systems running from higher altitudes in the northwest to the plains and deltas of the south. Among the biggest rivers are the Mekong, the Brahmaputra, the Red River in North Vietnam, the Salween and Irrawaddy rivers in Myanmar, the Pearl and Yangzi rivers in China, and the Chaophraya in central Thailand. The lower reaches of these river systems are well-fertilized plains, which have attracted people partly because of the mobility the environment affords, but also because of the suitability for paddy rice farming. Paddy farming, in which rice plants are 


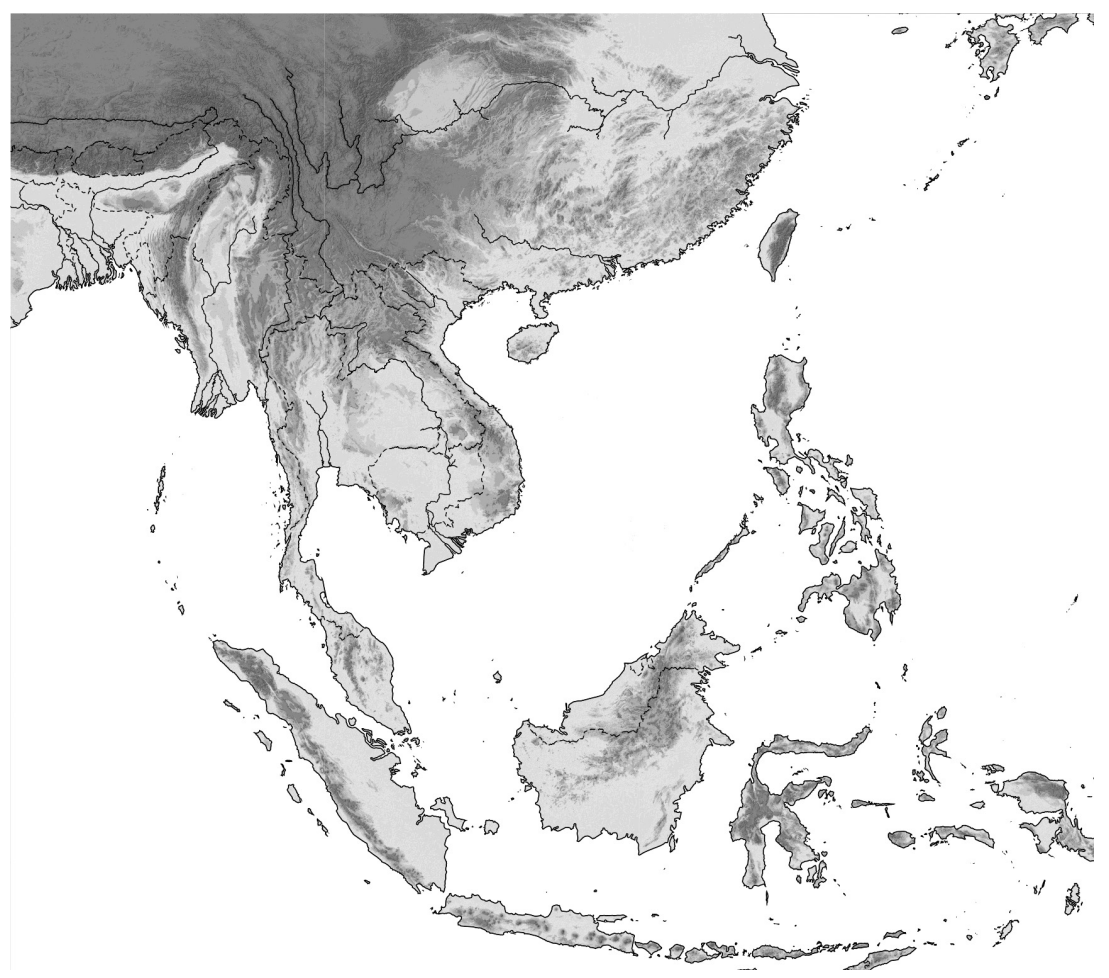

Map 25.1 Greater Mainland Southeast Asia: present-day Cambodia, Laos, Peninsular Malaysia, Thailand, Myanmar and Vietnam, along with China south of the Yangzi River, Northeast India and Insular Southeast Asia

kept continually flooded as they grow, requires management of water via systems of dikes and channels (Hartmann 1998). This method is significantly more productive than upland dry-field methods and can support larger populations (Bellwood 1992: 90). It also reduces biodiversity.

MSEA has seen a long and complex history of human movement, contact and diversification. Evidence from genetics and archaeology suggests that there has been human activity in the area since some 40,000 years ago, when conditions were very different from today. At around 20,000 years ago, global sea levels were $120 \mathrm{~m}$ lower than now (Chappell and Shackleton 1986; Tooley and Shennan 1987), implying different possibilities for human movement and livelihoods. Then, one could walk on dry land in a straight line from the site of present-day Ho Chi Minh City to Kuala Lumpur, and then in another straight line to Bali and again up to Brunei (Oppenheimer 2011; Voris 2000; White 2011). While a fair amount is known from bioarchaeological evidence about more recent human activity in the pre-agricultural period (Oxenham and Tayles 2006), the time horizon of comparative linguistics is limited to the last few thousand years (for recent reviews, see Enfield 2011b). Just behind that horizon are the beginnings of agriculture in MSEA some 4,000 or so years ago. 


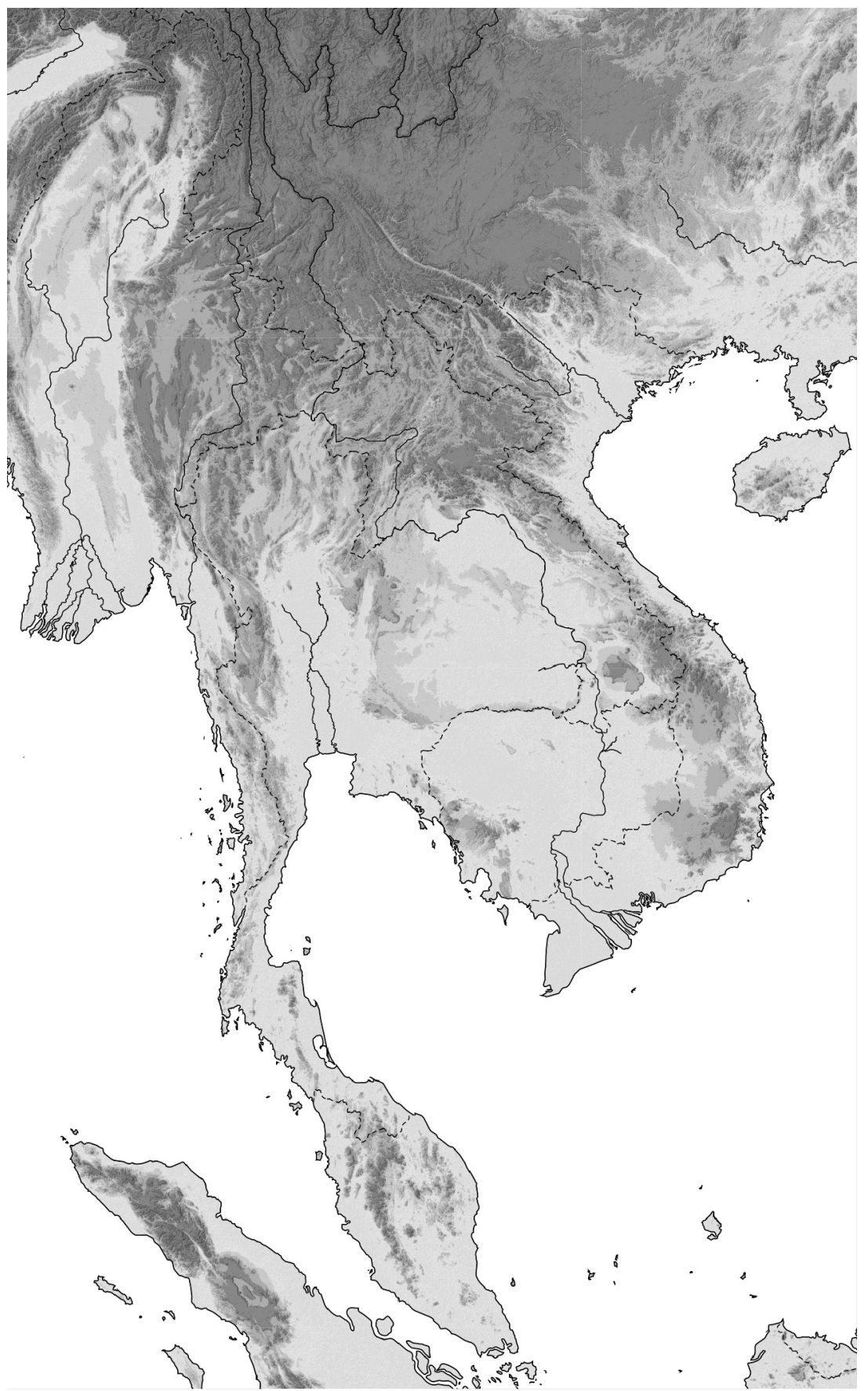

Map 25.2 Core Mainland Southeast Asia: present-day Cambodia, Laos, Vietnam, Thailand, and neighbouring parts of China, Malaysia and Myanmar 
A widely accepted view is that the people of MSEA once spoke Austroasiatic languages in a 'continuous distribution', and that this distribution was 'broken up by the historical expansions of the Chinese, Tai, Vietnamese, Burman and Austronesian (Malay and Cham) peoples' (Bellwood 1992: 109; cf. Sidwell and Blench 2011: 338 and passim; Post 2011). By what mechanism did this take place? Some have argued that modern ethnolinguistic diversification in MSEA was associated with demic diffusion (Bellwood 1992; Blust 1994; Edmondson and Gregerson 2007; Higham 2002). This implies the incoming migration of groups of people who rely on agriculture and who can thereby support large populations. The incomers replace less populous and less powerful existing forager populations (Ammerman and Cavalli-Sforza 1971; Cavalli-Sforza, Menozzi and Piazza 1993; Nichols 1992). ${ }^{1}$ An alternative to demic diffusion is cultural diffusion, whereby resident populations remain in place, but adopt new practices and ways of speaking. According to O'Connor (1995: 987), 'there is no direct evidence that an actual influx of immigrants ever displaced earlier peoples' in MSEA. He argues instead that an 'agricultural paradigm' is what diffused, bringing with it a 'society-shaping complex' (see Jonsson 2011, 2014 for discussion). For other critiques of the application of a demic diffusion model in MSEA see White (2011) on the view that hunter-gatherer communities have played a central role in shaping modern MSEA ethnographic diversity, and Fix (2011) on the genetics of ethnolinguistic diversification, in which he presents an alternative to the standard account of demic diffusion in the Malay Peninsula, with a model he calls trickle-effect colonization.

Regardless of whether one thinks the historical process of peopling and ethnolinguistic diversification in MSEA was driven primarily by the spread of people or by the spread of ideas - here, more work is needed - the modern distribution of ethnolinguistic groups is clear. In lowland areas, populations are denser, more culturally and linguistically homogeneous, and more closely affiliated with state political power. In upland areas, populations are sparser, more culturally and linguistically diverse, and have limited if any access to infrastructure, education or power. The dominant lowland populations are clearly distinct from each other in terms of political identity ('the Thai' versus ‘the Lao' versus ‘the Khmer', etc.), but the upland minority populations that straddle these nations have something in common: they are politically and geographically marginalized.

The upland areas in which many MSEA minorities live are conjoined in a single, elongated area, crossing political borders and encompassing

\footnotetext{
Demic diffusion is the spread of genes. It is usually associated with the outcomes of migration. In world history, this has often involved the movement of groups who have adopted agriculture, and who are therefore more populous and viable than those (e.g. hunter-gatherers) who are resident in the area being entered. Demic diffusion may be associated with population displacement or replacement, but this need not necessarily be the case. There may be genetic admixture between an incoming population and a resident population, such that some fraction of the genes of the resident population survives. Thanks to Mark Stoneking and Dan Dediu for clarification of these points.
} 
'virtually all the lands at altitudes above roughly three hundred meters all the way from the Central Highlands of Vietnam to northeastern India' (Scott 2009: ix). This area has been referred to as Zomia, a term coined by van Schendel (2002) in making the point that arbitrary research areas can be constructed and reified by 'academic politics', as he puts it (cf. Michaud 2010). Van Schendel's proposal of a Zomia area is a conceptual exercise, useful because it counteracts the politically sanctioned alternatives. The term has gained some recognition (though ironically not without danger of creating the reification it was warning against: Jonsson 2011, 2014), particularly due to Scott (2009). According to Scott, it is not that the inhabitants of Zomia simply share the fate of having been marginalized by states. Instead, he argues, they share a cultural distaste for being governed: they have chosen to remain isolated from central government control.

We do not have space in this chapter for more on the detailed history of human activity - peopling and migration, social contact and cultural shift, state formation and avoidance, war and peace - in MSEA. For further information, see Tarling (1992), Scott (2009) and Enfield (2011b).

\subsection{Mainland Southeast Asian Languages}

The degree of linguistic diversity in MSEA (i.e. the number of languages per square $\mathrm{km}$ ) is high (Enfield 2011c), and it is highest in upland areas. Lower language density in lowland areas is likely related in part to geographical factors and their implications for the nature of social networks (see Nettle 1999). In historical demographic processes of the kinds noted above, formerly diverse lowland communities in MSEA have become homogenized by a combination of two processes. One process was ethnolinguistic shift. Some groups stayed where they were but stopped passing on their languages and identities to their children, instead adopting the languages and identities of new dominant groups. This process can be observed all over MSEA today. Another process was out-migration, typically to more isolated hill areas (Scott 2009). Geographical isolation is a force that still promotes language diversity in the region, where former diversity of lowland areas is on its last legs. Many of the lowland languages are heavily endangered or extinct (Bradley 2007; Enfield 2006; Suwilai Premsrirat 2007). This is quickened by effects of the concentration of political power of modern nation states in the lowlands. In recent decades, processes of language standardization in MSEA nations (Simpson 2007) have helped to heavily reduce language diversity.

The languages of MSEA are from five major language families: SinoTibetan, Tai-Kadai, Hmong-Mien, Austroasiatic and Austronesian. ${ }^{2}$ There

\footnotetext{
2 The Andamanese languages are located just outside MSEA as defined here, though we note with interest new work on these lesser-known languages: see Abbi's recent reference grammar (2013) and dictionary (2012) of Great Andamanese.
} 
Table 25.1 A breakdown of numbers of languages in MSEA, separated into language families

\begin{tabular}{lll}
\hline \hline & Core MSEA & Greater MSEA \\
\hline Austroasiatic & $122(44 \%)$ & $138(24 \%)$ \\
Sino-Tibetan & $74(26 \%)$ & $288(49 \%)$ \\
Tai-Kadai & $51(18 \%)$ & $93(16 \%)$ \\
Austronesian & $25(9 \%)$ & $26(4 \%)$ \\
Hmong-Mien & $8(3 \%)$ & $38(7 \%)$ \\
Total & 280 & 583 \\
\hline \hline
\end{tabular}

are nearly 600 distinct languages spoken in Greater MSEA. ${ }^{3}$ If we exclude the China and India data, thus representing the Core MSEA area, the number of languages is about half this amount; see Table 25.1.

The very high linguistic diversity (i.e. the number of languages) in northeastern India and southern/southwestern China adds dramatically to the number of languages included in the area. It also reverses the relative proportion of Sino-Tibetan and Austroasiatic languages.

The MSEA area is unusual in global terms in that there is good agreement among scholars as to the basic language family affiliation of known languages. There are unresolved issues about lower-level subgroupings and there are unresolved hypotheses about possible macro-groupings. But for every known language, scholars agree as to which of the five main language families it fits into. This is unusual, firstly because it means that each language's basic affiliation is apparently uncontroversial and secondly because it suggests that there are no language isolates (Blench 2011: 125-126). ${ }^{4}$ For a survey of the historical-linguistic background, see Sidwell (2013).

Following is a list of some of the typological features that characterize MSEA languages (drawing mostly from Enfield 2005: 186-190, and 2011c: 69-70; see further references there).

\section{Sound system features}

- Large vowel systems. It is sometimes difficult to determine how many vowels a system has. There are alternative analyses of features such as diphthongs and phonation splits.

\footnotetext{
3 Data are from glottolog.org, accessed in May 2014. Many thanks to Harald Hammarström for his input and assistance. Core MSEA was defined for this count as Cambodia, Laos, Myanmar, Thailand and Vietnam; Greater MSEA included this, along with Peninsular Malaysia, areas of India east of 90 degrees (i.e. the states of Arunachal Pradesh, Nagaland, Manipur, Mizoram, Assam, Meghalaya and Tripura) and China south of the Yangzi river (specifically, the provinces of Zhejiang, Jiangxi, Hunan, Guizhou, Yunnan, Guangxi, Guangdong, Fujian and Hainan).

${ }^{4}$ Not considered in this chapter are sign languages. The sign language used in Ban Khor, Thailand (Nonaka 2004) appears to be an isolate, and there are surely more of its kind. Among spoken languages in MSEA there is Kenaboi, now extinct, and known only from two early twentieth century word lists. Hajek (1998) refers to Kenaboi as 'unclassified' but does not call it an isolate. Benjamin (2006) summarizes and analyses the available data as far as is possible. His view is that Kenaboi is 'a specially-invented form of speech', a 'taboo-jargon' associated with forest collecting trade. Kenaboi had large proportions of both Austroasiatic and Austronesian vocabulary, along with some unexplained forms. The data are too tenuous to establish whether it was an isolate or not.
} 
- Common underlying structure of vowel phoneme system, often 9-place, symmetrical, hi-mid-low by front-central-back.

- Long versus short vowel distinctions.

- Many more consonants are possible in initial position than in final position. Syllables have an initial-and-rhyme structure.

- Preference for one (major) syllable per word, with many languages featuring minor syllables or pre-syllables in an iambic pattern; see Pittayaporn (2015), Butler (2015), Post (2015) and Brunelle and Kirby (2015).

- Lexical contrast is marked by laryngeal features including pitch and phonation type, often in combination. Tone systems are complex: number of tones ranges from 4 to 15, with counts for a language differing depending on the analysis chosen. Phonation type systems usually distinguish two registers, e.g. 'clear' versus 'breathy'. Lexically contrastive pitch and phonation type are strongly correlated in functional and historical terms.

- Gap in voiced stop series at velar place of articulation (no voiced 'g').

\section{Morphosyntax-semantics system features}

- No inflectional morphology: no case, gender, number or definiteness marked on noun phrases, no agreement or tense-marking on verbs. Note that derivational morphology is widespread and sometimes highly productive in Austroasiatic languages of MSEA (see Alves 2015).

- Open class items - mostly nouns and verbs - serve functions that are expressed by dedicated functional morphemes (including bound morphology) in other languages, e.g., nominals as prepositions, verbs as aspect markers, comparative markers, adversative passive markers and valence-changing devices (Ansaldo 1999; Clark and Prasithrathsint 1985; Kölver 1991).

- Widespread use of verb serialization (meaning a range of different kinds of predicative structures that use combinations of verbs), with a rich array of types and functions in each language (Bisang 1991).

- Order of major constituents of the clause tends to be relatively flexible within languages, sensitive to pragmatic factors (though verb-object constituent order is dominant). Noun phrases tend to be left-headed and may have discontinuous constituents, especially when classifiers are involved.

- Zero anaphora: noun phrases may be ellipsed when their referents are contextually retrievable. This combined with flexibility in constituent order results in quite variable surface options; for a case study see Enfield (2007: 271-284).

- Extensive use of topic-comment structure in clauses.

- Large set of labile or ambitransitive verbs, especially of the causative/ inchoative or unaccusative type (e.g. Lao hak2 can mean transitive 'snap' or intransitive 'is/has been snapped'). 
- Rich inventories of sentence-final particles that make subtle distinctions in sentence type, stance, evidentiality and combinations thereof.

- Rich inventories of ideophones (or 'expressives') and other expressive forms, including rhyming four-syllable expressions and productive elaborative rhyming devices.

- Numeral classifiers and related systems of nominal classification (see Blench 2015).

- Complex pronominal systems, with multi-level social-deictic meanings.

Some of the most noteworthy commonalities among MSEA languages concern their lack of marking of certain semantico-grammatical categories. Most notably, as remarked upon in the list above, the languages almost entirely lack inflectional morphology in the usual sense of that term (i.e. including agreement, case, gender/number/definiteness on noun phrases, tense-marking on verbs). For an overview of selected national languages, see Comrie (1990), while Goddard (2005) presents a more topic-oriented approach; see also Vittrant and Watkins (in press).

\subsection{Linguistics of MSEA: Resources and Developments}

\subsubsection{Conferences and Publications}

The community of scholars working on MSEA linguistics is steadily growing. The South East Asia Linguistic Society (SEALS) - founded by Martha Ratliff and Eric Schiller at Wayne State University, Detroit, in 1990 - held its 25th annual meeting in 2015. Prior to 2009, proceedings of SEALS meetings were published in edited volumes. Since then they have appeared in the open-access Journal of the Southeast Asian Linguistics Society (for which, see www.jseals.org/). The SEAlang Projects website (www.sealang.net) is an invaluable resource that makes accessible a range of primary and secondary sources on MSEA languages. Other regular publishing venues for research on MSEA languages include the journals Mon-Khmer Studies (an open-access journal, see www.mksjournal .org/) and Linguistics of the Tibeto-Burman Area (see sealang.net/sala/ltba/ $\mathrm{htm} /$ index.htm). Some recent interdisciplinary explorations of ethnolinguistic diversification have focused on languages of MSEA and neighbouring places (e.g. Enfield 2011b; Sagart, Blench and Sanchez-Maras 2005). The last 10 years have seen the publication of multiple landmark overviews of MSEA language families, including Tai-Kadai (Diller, Edmondson and Luo 2008), Sino-Tibetan (Thurgood and LaPolla 2003; cf. Matisoff 2003a), Austroasiatic (Jenny and Sidwell 2015; cf. Shorto 2006), and the Austronesian languages of MSEA (Blust 2013b: 70-75; Grant and Sidwell 2005; Larish 2005; Thurgood 1999). 


\subsubsection{New Descriptive Work}

A key measure of progress in an area is the production of reference materials based on new empirical research. ${ }^{5}$ Full-sized descriptions of MSEA languages published since the turn of the century include grammars of Semelai (Kruspe 2004), Jahai (Burenhult 2005), Garo (Burling 2004), Deuri (Jacquesson 2004), Mongsen Ao (Coupe 2007), Lao (Enfield 2007), Anong (Sun and Liu 2009), Hainan Cham (Thurgood, Thurgood and Li 2014), Turung (Morey 2010), the Tai languages of Assam (Morey 2005), Lisu (Yu 2007), Thai (Higbie and Thinsan 2003; Iwasaki and Ingkaphirom Horie 2005) and Cambodian (Haiman 2011). Numerous grammars have been completed as $\mathrm{PhD}$ dissertations; just in the area of northeast India, for example, see grammars of Galo (Post 2007), Atong (van Breugel 2014) and Karbi (Konnerth 2014). Sketches or partial descriptions have appeared on languages including Pacoh (Alves 2006), Kri (Enfield and Diffloth 2009) and Arem (Ferlus 2014), and detailed descriptions have appeared of specific domains of grammar such as phonetics/phonology; see for example Watkins (2002) on Wa and Coupe (2003) on Ao. Major dictionaries of minority languages are less abundant; two notable examples are Watkins (2013) on Wa and Svantesson et al. (2013) on Kammu Yùan. An important preoccupation of descriptive linguistics globally is the documentation of endangered languages; for excellent examples of new empirical work with this orientation in the MSEA context, see Morey (2005, 2010; see also Suwilai Premsrirat 1998, 2008).

A significant amount of new data and analysis from MSEA languages has become available on most if not all domains of interest to linguists, and on most if not all language families and subareas of MSEA. As just one example, here we mention the Aslian languages of Peninsular Malaysia. In the last decade or so, we have seen the publication of typological overviews of the Aslian languages as a group (Matisoff 2003b), new reference grammars (Burenhult 2005; Kruspe 2004), other descriptive materials (Burenhult and Wegener 2009; Wnuk 2016), new interdisciplinary research on the history and diversification of ethnolinguistic subgroups (Bulbeck 2011; Burenhult, Kruspe and Dunn 2011; Dunn et al. 2011; Dunn, Kruspe and Burenhult 2013; Fix 2011; Oppenheimer 2011), and field research on the psychological implications of semantic systems that are indigenous to Aslian languages and world views (Burenhult and Majid 2011; Majid and Burenhult 2014; Wnuk and Majid 2014). Not only is this breadth and depth of new work improving our basic understanding of MSEA languages and their sociohistorical contexts, it is also helping to

\footnotetext{
${ }^{5}$ We mention here only a selection of those recent materials that have been published in English, though we note that a substantial descriptive literature on MSEA languages is being published in other languages, including Chinese, French, Indonesian, Thai and Vietnamese. For some examples, see Bo (2002), Bon (2014), Buakaw (2012), Chen (2005), Gai (2002), Giaphong (2004), Kosaka (2000), D. Li (2003, 2004), Y. Li (2003), Lidz (2010), Zongwu Mao and Yunbing Li (2002, 2007), Mayuree (2006), Ploykaew (2001), Samarina (2011), Seng Mai (2012), Shee (2008), Shintani (2008), Srisakorn (2008), Wayesha (2010).
} 
balance our perspective on the MSEA area, with effects on our image of what a Southeast Asian language is typically like (see below). The availability of new descriptive materials means that we can progress in the field by testing existing proposals and by continuously expanding the scope of our work (see Pittayaporn 2009 for a good illustration of this point).

\subsubsection{New Methods}

As new methods in linguistic research are being developed and applied in linguistics globally, so they are being developed and applied in Mainland Southeast Asia. In phonetics and phonology, for example, new instrumental and computational technologies are rapidly transforming the realms of possibility in data collection and analysis, both by making new kinds of measurement possible and by making the equipment smaller and more portable for fieldwork; see Edmondson and Esling (2006: 172-175) for the use of laryngoscopy to study the phonetics of breathy vocal register in Jianchuan Bai (spoken in Yunnan), and Brunelle (2009) for the use of electroglottography to study register in Cham dialects in Vietnam (see also Brunelle, Nguyễn and Nguyễn 2010 on Northern Vietnamese). Newly developed statistical techniques are being applied with interesting results: in historical linguistics, probability-based bioinformatic techniques are being used for exploring cladistic representations of language relatedness (see for example Burenhult, Kruspe and Dunn 2011), and in areal typology, statistical modelling is being used to test dependencies among phonological features, language history and language contact (Brunelle and Kirby, Chapter 26, this volume). In lexical and grammatical work, new field methods are being applied in the exploration of semantic fields, in a range of functional and conceptual domains (see e.g. Burenhult 2006; Enfield 2015; Wnuk and Majid 2014). There is an increasing interest in combining methods in order to further our knowledge of the area's languages, for example in the interdisciplinary collaborations of historical work (van Driem 2007; Enfield 2011b; Sagart et al. 2005). And computational power is being exploited in building larger and better databases of, or including, MSEA languages (Donohue et al. 2013; Dryer and Haspelmath 2013).

\subsubsection{Historical-comparative Linguistics}

Research in historical-comparative linguistics continues apace in MSEA. At the level of subgrouping, advances are being made in all the major language families. Old hypotheses are being tested with new data and techniques, and new hypotheses are being put forward. The appearance of new data, in particular, has made an important difference, enabling, for example, Pittayaporn (2009) to propose a new reconstruction of 
Proto-Southwestern Tai phonology, Sidwell (2009) to offer an improved account of vowels in Proto-Mon-Khmer, and Matisoff (2015; cf. Matisoff 2003a) to re-examine the place of the Jingpho language within TibetoBurman. In research on historical Hmong-Mien, Ratliff (2010) has recently provided an assessment of previous work and offers substantial new reconstructions, with consideration of their implications. Historical Austroasiatic has seen substantial developments, including a suspension of the assumption of a highest-level split between Munda and Mon-Khmer. It is no longer widely assumed that 'MonKhmer languages' represent descendants of a single ancestor language below Proto-Austroasiatic, although the term is still useful with the meaning 'non-Munda Austroasiatic languages'; for a range of perspectives on this, see discussion in Sidwell and Blench (2011), Diffloth (2011), Sagart (2011) and van Driem (2011). Similarly, in Sino-Tibetan linguistics, assumptions are being questioned. For example, recent reconsiderations of the position of Chinese in the family have assigned it to a lower-level subgroup rather than the standard placement as a high major branch; more subgroups of Sino-Tibetan are identified, and the time depth of reconstructed Proto-Sinitic is pushed back to well before Old Chinese (Blench and Post 2013; van Driem 2013).

\subsubsection{Language in Social Life}

Numerous lines of work in linguistics deal with the role of language in social life. An important theme in recent work in MSEA is the sociolinguistics of language endangerment, and associated issues including language protection and revitalization; for an example, see Phattharathanit (2012) on identity maintenance in Lanna (cf. Bradley 2007; Suwilai Premsrirat 2007). Research on linguistic politeness continues, mostly in relation to national languages, and with reference to the languages' elaborated systems of social deixis, for example in their systems of personal pronouns, and the pragmatic alternatives that effectively create open class systems for person reference (Cooke 1968; Enfield 2015: Ch. 5; Haas 1969; Luong 1990). The more complex documented systems of person reference are those belonging to the major literate languages of the area, including Thai, Cambodian, Vietnamese and Burmese (Cooke 1968). There has been recent work in this domain on languages including Lao (Enfield 2007: Ch. 5; 2015: Ch. 5). On Vietnamese, see Sophana (2008) on politeness strategies, and Sidnell and Shohet (2013) on avoidance strategies (see also Luong 1988). Linking social life to central concerns of historical linguistics and typology, there has been recent work on sociolinguistic conditions for borrowing (Alves 2009); for similar work see Thurgood (2010) comparing two varieties of Cham with the Tibeto-Burman language Anong. A new line of work in MSEA is conversation analysis: Enfield (2013) presents several case studies of Lao language in conversation; Hạ $(2010,2013)$ presents studies of 
Vietnamese conversation with a focus on the role of prosody, for example in repair and backchannelling (see also Umaporn 2007 on backchannelling in Mon).

\subsubsection{Changing Perceptions}

Like in any area, linguistics in MSEA is subject to preconceptions. As soon as an idea becomes something of an orthodoxy it is right to revisit and question it. A trend in recent scholarship of MSEA languages has been to raise and sometimes challenge certain assumptions about the linguistics of this area.

\subsubsection{The Idea of a Typical MSEA Language}

Comrie (2007: 45) finds that, on measures taken using data from The World Atlas of Language Structures (Haspelmath et al. 2005), 'Thai turns out to be the most typical of the three major national languages of Mainland Southeast Asia considered here. ${ }^{6}$ This conclusion is shared by Dahl (2008). This of course does not mean that Thai is the most typical of all MSEA languages, although this is often assumed to be the case. The national languages of the area are the better-described and better-known languages, and they happen to share many typological features that characterize Thai, such as a tendency for monosyllabicity, a lack of productive affixation, and an elaborate numeral classifier system. But there are many MSEA languages whose properties differ from these and many other properties found in Thai and other national languages like Vietnamese. In fact, many languages of the area lack these features. Within MSEA linguistics one's view of what is typical may depend on one's academic background, and, especially, on which language one worked on first, or has worked on most, in one's research career. If, for example, one's earliest and most in-depth work on MSEA languages was on Lao (as is the case with the present author), then languages like Lao and Thai would seem typical. They are typologically very similar to other major languages like Vietnamese. Another researcher's background would suggest otherwise. The viewpoint professed by our colleague Gérard Diffloth is that a typical MSEA language lacks lexical tone, has complex phonotactics including syllable-initial consonant clusters, and has productive derivational morphology, quite a contrast from the oft-cited set of features of MSEA languages; see Henderson (1965), Capell (1979), Suwilai Premsrirat (1987) and Kruspe (2004); cf. Alves (2001, 2015). The problem with treating the area's major national languages as reference points is not only that they are a tiny sample but that they are known to be not like the rest, due to factors including (1) they are spoken by very large, often urbanized populations,

\footnotetext{
${ }^{6}$ The idea that a language may be 'typical' of an area seems to be an intuitive one, but the relevant sense in which a language can be said to be typical is seldom defined.
} 
(2) they are spoken as second languages by large sections of the population,

(3) they are official languages, used in major education systems, media and broadcasting, and legal documents.

\subsubsection{Nominal Classification}

MSEA is often cited in typologies of nominal classification as an area that has numeral classifiers (Aikhenvald 2000; Grinevald 2000). Recent research shows that systems of nominal classification in MSEA can be more complex than this. They not only contain the classic numeral classifier type, consisting of a large set of classificatory nominals that are used whenever something is being numerated, but also systems that resemble the noun class systems found widely in Africa and the Amazon, and ancillary systems that resemble numeral classifiers but which are involved in the use of more simple modifiers such as demonstratives and specifiers. Enfield (2007: 119-156) shows that in Lao there are in fact four distinct grammatical systems of nominal classification, of which numeral classifiers are one (see Blench 2015).

\subsubsection{Sesquisyllables}

Researchers of the sound structure of words in MSEA languages often refer to the idea of 'sesquisyllables' and even the property of 'sesquisyllabicity'. This term was introduced by Matisoff (1973) to refer to the 'one-and-a-half syllable' form of words found in many MSEA languages (Butler 2015; Henderson 1952; Pittayaporn 2015; Shorto 1960). The term has not always been applied in an exact or consistent way. In a narrow sense, it can refer specifically to a syllable with schwa epenthesis between elements of an initial consonant cluster; that is, a syllable whose onset is phonologically /CC/ but phonetically $\left[\mathrm{C}^{\circ} \mathrm{C}\right]$. In a broad sense, it can refer to any word that has an iambic structure, with the main stressed syllable coming at the end. Consider the following three words in Kri (Enfield and Diffloth 2009): /cakaay/ [caka:y] 'to measure something by handspans', /ckaay/ [c $\left.{ }^{\circ} \mathrm{ka}: \mathrm{y}\right]$ 'a hand span', and /caan/ [ca:y] 'buttress of a tree' (or /kaay?/ [ka:y?] 'chin/jaw'). In the broad sense, both /cakaay/ [caka:n] and /ckaay/ [ $\left.{ }^{\circ} \mathrm{ka}: \mathrm{n}\right]$ are sesquisyllabic, while in the narrow sense, only /ckaay/ [ $\left.{ }^{\circ} \mathrm{ka}: \mathrm{n}\right]$ is. Recent work - by Butler (2015) and Pittayaporn (2015) - has made a significant advance not only by insisting that we be consistent and precise in the use of such terms, but by turning to empirical and theoretical accounts in order to offer motivated solutions, making the intuitive idea of sesquisyllabicity accountable to current theory and data in theoretical phonology and articulatory phonetics. Butler (2015) calls for more thoughtful consideration of the terms, and seeks to make progress by holding certain phonological ideas of syllable structure accountable to phonetic behaviour that can be experimentally tested. Pittayaporn (2015) takes a broader 
comparative approach to the problem, offering a typology of sesquisyllabic languages, defining the distinct meanings that this term can have.

\subsubsection{Tone Phonetics and Phonology}

An oft-cited feature of MSEA languages is that many of them are tone languages. When asked what this means, most linguists would agree with Yip (2002: 1): 'A language is a "tone language" if the pitch of the word can change the meaning of the word.' But as linguists of MSEA languages since Henderson $(1952,1965,1967)$ have insisted, it is wrong to think that pitch is the sole or defining feature of a tone system in MSEA (see Brunelle and Kirby 2015 and Sidwell 2015; see also Abramson and L-Thongkum 2009): 'It is important to recognize that pitch is frequently only one of the phonetic components of "tone" as a phonological category ... A phonological tone is in our area very frequently a complex of other features besides pitch - such as intensity, duration, voice quality, final glottal constriction and so on' (Henderson 1967: 171). From this perspective, while tone and phonation type are sometimes considered to be distinct phonological organizations, they should instead be treated as instances of a single sound system property insofar as they each involve the use of laryngeal features for lexical contrast. Pitch contours, distinctions in phonation and other glottalic effects are all produced in the larynx, by the vocal folds, and are all articulatorily independent of segmental speech sounds produced with the lips, teeth and tongue (i.e. consonants). Tone and phonation are intimately bound and not essentially distinct. For this reason we recognize that the sound system of an MSEA 'tone' language, such as Vietnamese, is not of a different species from that of a classical MSEA 'register' or 'phonation type' language such as Kri (Enfield and Diffloth 2009). Most systems that are identified as one or the other (in phonological terms) actually display properties of both (in phonetic terms).

\subsubsection{MSEA as a Linguistic Area}

In research on areal linguistics, a great deal of new empirical and conceptual work from around the world has improved our understanding of historical processes of ethnolinguistic diversification, contact and convergence, while at the same time some of the basic tenets of areal linguistics have come under question (Muysken 2008; Stolz 2002). MSEA has been widely regarded as a classic linguistic area with close parallelism in structure between neighbouring languages that have no demonstrable common ancestor: see Henderson (1965), Capell (1979), Clark (1989), Matisoff (1991), Bisang (1991), Enfield (2005), Comrie (2007), Dahl (2008) and Vittrant and Watkins (in press). The cause of this parallelism is widely assumed to be language contact. While much work examines typological parallels across language families and interprets these as evidence of effects from language contact, recent work by Sidwell (2015), Ratliff 
(2015) and Brunelle and Kirby (2015) calls for caution in jumping to that conclusion. If neighbouring but unrelated languages share typological features this can also be a result of parallel language-internal development (Enfield 2005; Thurgood 1998). That possibility is equally deserving of consideration, and so the idea that convergence is due to contact should not be assumed without question.

\subsection{Summary}

Languages in the Mainland Southeast Asia area are well known for their seemingly high degree of convergence in many - if not all - aspects of their grammar. Recent empirical and theoretical advances in the study of Mainland Southeast Asian languages are driving important developments in our understanding of the area. While much new work is confirming and enriching our understanding of known patterns of structure in the area, other contributions are challenging orthodoxy, including the idea of what a 'typical' Mainland Southeast Asian language is like, and even the very notion that the high degree of convergence in the area is a direct result of social contact among historical speech communities.

\section{Acknowledgements}

This chapter draws directly on sections of a chapter co-authored with Bernard Comrie that appeared as the introduction to our 2015 edited book Languages of Mainland Southeast Asia: The State of the Art (2015): I thank Bernard for allowing me to revise and submit this chapter, based on our earlier co-authored work. For financial support, I am grateful to the Max Planck Institute for Evolutionary Anthropology (Department of Linguistics), the Max Planck Institute for Psycholinguistics (Language and Cognition Department), and the European Research Council (through grant 240853 'Human Sociality and Systems of Language Use'). I would like to thank Maarten van den Heuvel for technical assistance in preparing the manuscript for publication, and Angela Terrill at Punctilious Editing (www.punctilious.net/) for copy-editing. For comments and suggestions on a draft, I thank Roger Blench, Jeremy Collins, Bernard Comrie, Mark Donohue, David Gil, Pittayawat Pittayaporn, Mark Post, Martha Ratliff and Paul Sidwell.

\section{References}

Abbi, Anvita, 2012. Dictionary of the Great Andamanese Language: English-Great Andamanese-Hindi. Delhi: Ratna Sagar. 
Abbi, Anvita, 2013. A Grammar of the Great Andamanese Language: An Ethnolinguistic Study. Leiden: Brill Academic.

Abramson, Arthur S. and Theraphan L-Thongkum, 2009. A fuzzy boundary between tone languages and voice-register languages. In Gunnar Fant, Hiroya Fujisaki and Jiaxuen Shen (eds), Frontiers in Phonetics and Speech Science, pp. 149-155. Beijing: The Commercial Press.

Adelaar, Alexander and Nikolaus P. Himmelmann, 2005. The Austronesian Languages of Asia and Madagascar. London: Routledge Curzon.

Aikhenvald, Alexandra Y., 2000. Classifiers: A Typology of Noun Categorization Devices. Oxford: Oxford University Press.

Alves, Mark J., 2001. What's so Chinese about Vietnamese? In Graham W. Thurgood (ed.), Papers from the Ninth Annual Meeting of the Southeast Asian Linguistics Society, pp. 221-242. Phoenix: Arizona State University.

Alves, Mark J., 2006. A Grammar of Pacoh: A Mon-Khmer Language of the Central Highlands of Vietnam (Shorter Grammars). Pacific Linguistics, vol. 580. Canberra: Australian National University.

Alves, Mark. J., 2009. Sino-Vietnamese grammatical vocabulary and sociolinguistic conditions for borrowing. Journal of the Southeast Asian Linguistics Society 1: 1-9.

Alves, Mark J., 2015. Morphological functions among Mon-Khmer languages: Beyond the basics. In Enfield and Comrie (eds), pp. 524-550.

Ammerman, Albert J. and Luigi L. Cavalli-Sforza, 1971. Measuring the rate of spread of early farming in Europe. Man 6 (4): 674-688.

Ansaldo, Umberto, 1999. Comparative Constructions in Sinitic: Areal Typology and Patterns of Grammaticalisation. Dissertation, Stockholm University, Stockholm.

Ansaldo, Umberto and Stephen J. Matthews, 2001. Typical creoles and simple languages: The case of Sinitic. Linguistic Typology 5 (2/3): 311-324.

Bauer, Robert S., 1996. Identifying the Tai substratum in Cantonese. In PanAsiatic Linguistics: Proceedings of the Fourth International Symposium on Languages and Linguistics, vol. V, pp. 1806-1844. Bangkok: Mahidol University.

Bellwood, Peter, 1992. Southeast Asia before prehistory. In Tarling (ed.), vol. 1, pp. 55-136.

Benjamin, Geoffrey, 2006. Hervey's 'Kenaboi': Lost Malayan language or forest-collecting taboo jargon? Paper presented at the 10th International Association of Historians of Asia Conference, Singapore, October 1986.

Bisang, Walter, 1991. Verb serialization, grammaticalization and attractor positions in Chinese, Hmong, Vietnamese, Thai and Khmer. In Hansjakob Seiler and Waldfried Premper (eds), Partizipation: Das sprachliche Erfassen von Sachverhalten, pp. 509-562. Tübingen: Narr.

Blench, Roger, 2011. The role of agriculture in the evolution of Mainland Southeast Asian language phyla. In Enfield (ed.), pp. 125-152. 
Blench, Roger, 2015. The origins of nominal classification markers in MSEA languages: Convergence, contact and some African parallels. In Enfield and Comrie (eds), pp. 551-578.

Blench, Roger and Mark W. Post, 2013. Re-thinking Sino-Tibetan phylogeny from the perspective of North East Indian languages. In Nathan Hill and Thomas Owen-Smith (eds), Trans-Himalayan Linguistics, pp. 71-104. Berlin: Mouton de Gruyter.

Blust, Robert, 1994. The Austronesian settlement of Mainland Southeast Asia. In Karen L. Adams and Thomas John Hudak (eds), Papers from the Second Annual Meeting of the Southeast Asian Linguistics Society, pp. 25-83. Tempe, AZ: Arizona State University.

Blust, Robert, 2013a. Southeast Asian islands and Oceania: Austronesian linguistic history. In Peter Bellwood (ed.), The Encyclopedia of Global Human Migration, vol. 1: Prehistory. Oxford: Wiley-Blackwell.

Blust, Robert, 2013b. The Austronesian Languages (revised edition). Canberra: Asia-Pacific Linguistics.

Bo, Wenze, 2002. A Study of Mulao. Beijing: The Nationalities Press.

Bon, Noëllie, 2014. Une Grammaire de la Langue Stieng, Langue en Danger du Cambodge et du Vietnam. Dissertation, Université Lumière Lyon 2, Lyon.

Bradley, David, 1995. Papers in Southeast Asian Linguistics, vol. 13: Studies in Burmese Languages. Pacific Linguistics, vol. A-83. Canberra: Research School of Pacific and Asian Studies, Australian National University.

Bradley, David, 2007. Language endangerment in China and Mainland Southeast Asia. In Matthias Brenzinger (ed.), Language Diversity Endangered, pp. 278-302. Trends in Linguistics: Studies and Monographs. Berlin: Mouton de Gruyter.

van Breugel, Seino, 2014. A Grammar of Atong. Leiden: Brill.

Brunelle, Marc, 2009. Contact-induced change? Register in three Cham dialects. Journal of the Southeast Asian Linguistics Society 2: 1-22.

Brunelle, Marc and James Kirby, 2015. Re-assessing tonal diversity and geographical convergence in Mainland Southeast Asia. In Enfield and Comrie (eds), pp. 80-108.

Brunelle, Marc, Nguyễn Duy Dương and Nguyễn Khắc Hùng, 2010. A laryngographic and laryngoscopic study of Northern Vietnamese tones. Phonetica 67: 147-169.

Buakaw, Supakit, 2012. A Phonological Study of Palaung Dialects Spoken in Thailand and Myanmar, with Focuses on Vowels and Final Nasals. Doctoral dissertation, Mahidol University, Bangkok.

Bulbeck, David, 2011. Biological and cultural evolution in the population and culture history of Homo sapiens in Malaya. In Enfield (ed.), pp. 207-255.

Burenhult, Niclas, 2005. A Grammar of Jahai. Pacific Linguistics, vol. 566. Canberra: Australian National University.

Burenhult, Niclas, 2006. Body part terms in Jahai. Language Sciences 28: 162-180. 
Burenhult, Niclas, Nicole Kruspe and Michael Dunn, 2011. Language history and culture groups among Austroasiatic-speaking foragers of the Malay Peninsula. In Enfield (ed.), pp. 257-275.

Burenhult, Niclas and Asifa Majid, 2011. Olfaction in Aslian ideology and language. The Senses and Society 6 (1): 19-29.

Burenhult, Niclas and Claudia Wegener, 2009. Preliminary notes on the phonology, orthography and vocabulary of Semnam (Austroasiatic, Malay Peninsula). Journal of the Southeast Asian Linguistics Society 1: 283-312.

Burling, Robbins, 2004. The Language of the Modhipur Mandi (Garo), vol. I: Grammar. New Delhi: Bibliophile South Asia.

Butler, Becky, 2015. Approaching a phonological understanding of the sesquisyllable with phonetic evidence from Khmer and Bunong. In Enfield and Comrie (eds), pp. 437-493.

Capell, Arthur, 1979. Further typological studies in southeast Asian languages. In Nguyen Dang Liem (ed.), South-East Asian Linguistic Studies, vol. 3, pp. 1-42. Canberra: Pacific Linguistics.

Cavalli-Sforza, Luigi, Paolo Menozzi and Alberto Piazza, 1993. Demic expansions and human evolution. Science 259 (5095): 639-646.

Chappell, Hilary, 2001. Language contact and areal diffusion in Sinitic languages. In Alexandra Y. Aikhenvald and R. M. W. Dixon (eds), Areal Diffusion and Genetic Inheritance: Problems in Comparative Linguistics, pp. 328-357. Oxford: Oxford University Press.

Chappell, John and N. J. Shackleton, 1986. Oxygen isotopes and sea level. Nature 324 (6093): 137-140.

Chen, Guoqing, 2005. Kemieyu yanjiu [A Study of Kemie]. Beijing: Minzu chubanshe.

Clark, Marybeth, 1989. Hmong and areal South-East Asia. In David Bradley (ed.), Papers in Southeast Asian Linguistics, vol. 11: Southeast Asian Syntax, pp. 175-230. Canberra: Pacific Linguistics.

Clark, Marybeth and Amara Prasithrathsint, 1985. Synchronic lexical derivation in Southeast Asian languages. In Suriya Ratanakul and Suwilai Premsrirat (eds), Southeast Asian Linguistic Studies Presented to André-G. Haudricourt, pp. 34-81. Bangkok: Mahidol University.

Comrie, Bernard (ed.), 1990. The Major Languages of East and South-East Asia. London: Routledge.

Comrie, Bernard, 2007. Areal typology of mainland Southeast Asia: What we learn from the WALS maps. In Pranee Kullavanijaya (ed.), Trends in Thai Linguistics, pp. 18-47. Special issue of Manusya 13. Bangkok: Chulalongkorn University.

Cooke, Joseph R., 1968. Pronominal Reference in Thai, Burmese and Vietnamese. Berkeley, CA: University of California Press.

Coupe, A. R., 2003. A Phonetic and Phonological Description of Ao: A TibetoBurman Language of Nagaland, North-East India. Canberra: Pacific Linguistics. 
Coupe, A. R., 2007. A Grammar of Mongsen Ao. Mouton Grammar Library, vol. 39. Berlin: Mouton de Gruyter.

Dahl, Östen, 2008. An exercise in 'a posteriori' language sampling. Sprachtypologie und Universalienforschung 61 (3): 208-220.

Diffloth, Gérard, 2011. Austroasiatic word histories: Boat, husked rice and taro. In Enfield (ed.), pp. 295-313.

Diller, Anthony V. N., Jerold A. Edmondson and Yongxian Luo, 2008. The Tai-Kadai Languages. London: RoutledgeCurzon.

Donohue, Mark, Rebecca Hetherington, James McElvenny and Virginia Dawson, 2013. World Phonotactics Database. Canberra: Australian National University. http://phonotactics.anu.edu.au

van Driem, George, 2007. Austroasiatic phylogeny and the Austroasiatic homeland in light of recent population genetic studies. Mon-Khmer Studies 37: 1-14.

van Driem, George, 2011. Rice and the Austroasiatic and Hmong-Mien homelands. In Enfield (ed.), pp. 361-390.

van Driem, George, 2013. Trans-Himalayan. In Nathan Hill and Thomas Owen-Smith (eds), Trans-Himalayan Linguistics. Berlin: Mouton de Gruyter.

Dryer, Matthew S. and Martin Haspelmath (eds), 2013. The World Atlas of Language Structures Online. Leipzig: Max Planck Institute for Evolutionary Anthropology. http://wals.info

Dunn, Michael, Niclas Burenhult, Nicole Kruspe, Sylvia Tufvesson and Neele Becker, 2011. Aslian linguistic prehistory: A case study in computational phylogenetics. Diachronica 28 (3): 291-323.

Dunn, Michael, Nicole Kruspe and Niclas Burenhult, 2013. Time and place in the prehistory of the Aslian languages. Human Biology 85: 383-399.

Edmondson, Jerold A. and John H. Esling, 2006. The valves of the throat and their functioning in tone, vocal register and stress: laryngoscopic case studies. Phonology 23 (2): 157-191.

Edmondson, Jerold A. and Kenneth J. Gregerson, 2007. The languages of Vietnam: Mosaics and expansions. Language and Linguistics Compass 1 (6): 727-749.

Enfield, N. J., 2005. Areal linguistics and mainland Southeast Asia. Annual Review of Anthropology 34: 181-206.

Enfield, N. J., 2006. Languages as historical documents: The endangered archive in Laos. South East Asia Research 14 (3): 471-488.

Enfield, N. J., 2007. A Grammar of Lao. Mouton Grammar Library, vol. 38. Berlin: Mouton de Gruyter.

Enfield, N. J. (ed.), 2011a. Dynamics of Human Diversity: The Case of Mainland Southeast Asia. Canberra: Pacific Linguistics.

Enfield, N. J., 2011b. Introduction: Dynamics of Human Diversity in Mainland Southeast Asia. In Enfield (ed.) pp. 1-8.

Enfield, N. J., 2011c. Linguistic diversity in mainland Southeast Asia. In Enfield (ed.), pp. 63-80. 
Enfield, N. J., 2013. Relationship Thinking: Agency, Enchrony, and Human Sociality. New York: Oxford University Press.

Enfield, N. J., 2015. The Utility of Meaning: What Words Mean and Why. Oxford: Oxford University Press.

Enfield, N. J. and Bernard Comrie (eds), 2015. The Languages of Mainland Southeast Asia: The State of the Art. Berlin and Boston: Mouton de Gruyter.

Enfield, N. J. and Gérard Diffloth, 2009. Phonology and sketch grammar of Kri, a Vietic language of Laos. Cahiers de Linguistique - Asie Orientale 38 (1): 3-69.

Ferlus, Michel, 2014. Arem, a Vietic Language. Mon-Khmer Studies 43 (1): 1-15.

Fix, Alan, 2011. Origin of genetic diversity among Malaysian Orang Asli: An alternative to the demic diffusion model. In Enfield (ed.), pp. 277-291. Gai, Xingzhi, 2002. A Study of Tanglang. Beijing: The Nationalities Press.

Giaphong, Suchada, 2004. Plang Grammar as Spoken in Huay Namkhun Village, Chiang Rai Province. MA thesis, Mahidol University, Bangkok.

Gil, David, 2015. The Mekong-Mamberamo linguistic area. In Enfield and Comrie (eds), pp. 262-351.

Goddard, Cliff, 2005. The Languages of East and Southeast Asia. Oxford: Oxford University Press.

Grant, Anthony and Paul Sidwell, 2005. Chamic and Beyond: Studies in Mainland Austronesian Languages. Canberra: Pacific Linguistics.

Grinevald, Colette, 2000. A morphosyntactic typology of classifiers. In Gunter Senft (ed.), Systems of Nominal Classification, pp. 50-92.

Hạ, Kiều Phúong, 2010. Prosody of Vietnamese from an interactional perspective: $\grave{o}$, $\grave{u}$ and $v a ̂ n g$ in backchannels and requests for information. Journal of the Southeast Asian Linguistics Society 3 (1): 56-76.

Hạ, Kiều Phúóng, 2013. Prosodic means in repair initiation as an activity in Northern Vietnamese conversation. In Daniel Hole and Elisabeth Löbel (eds), Linguistics of Vietnamese: An International Survey, pp. 35-54. Berlin and New York: de Gruyter Mouton.

Haas, Mary Rosamond, 1969. Sibling terms as used by marriage partners. Southwestern Journal of Anthropology 25 (3): 228-235.

Haiman, John, 2011. Cambodian: Khmer. London Oriental and African Language Library, vol. 16. Amsterdam: John Benjamins.

Hajek, John, 1998. Kenaboi: An extinct unclassified language of the Malay Peninsula. Mon-Khmer Studies 28: 137-149.

Hartmann, John, 1998. A linguistic geography and history of Tai Meuang-Fai (Ditch-Dike) techno-culture. Language and Linguistics 16 (2): 67-101.

Haspelmath, Martin, Matthew S. Dryer, David Gil and Bernard Comrie (eds), 2005. The World Atlas of Language Structures. Oxford: Oxford University Press.

Henderson, Eugénie. J. A., 1952. The main features of Cambodian pronunciation. Bulletin of the School of Oriental and African Studies 14: 149-174. 
Henderson, Eugénie J. A., 1965. The topography of certain phonetic and morphological characteristics of South East Asian languages. Lingua 15: 400-434.

Henderson, Eugénie J. A., 1967. Grammar and tone in South East Asian languages. Wissenschaftliche Zeitschrift der Karl-Marx-Universität Leipzig 16 (1/2): 171-178.

Higbie, James and Snea Thinsan, 2003. Thai Reference Grammar: The Structure of Spoken Thai. Bangkok: Orchid Press.

Higham, C., 2002. Early Cultures of Mainland Southeast Asia. Bangkok: River Books.

Hyslop, Gwendolyn, Stephen Morey and Mark W. Post (eds), 2011. North East Indian Linguistics, vol. 3. New Delhi: Cambridge University Press India.

Hyslop, Gwendolyn, Stephen Morey and Mark W. Post (eds), 2012. North East Indian Linguistics, vol. 4. New Delhi: Cambridge University Press India.

Hyslop, Gwendolyn, Stephen Morey and Mark W. Post (eds), 2013. North East Indian Linguistics, vol. 5. New Delhi: Cambridge University Press India.

Iwasaki, Shoichi and Preeya Ingkaphirom Horie, 2005. A Reference Grammar of Thai. Cambridge: Cambridge University Press.

Jacquesson, François, 2004. Le Deuri: Langue Tibéto-Birmane d'Assam. Leuven, Paris and Dudley, MA: Peeters.

Jenny, Mathias and Paul Sidwell (eds), 2015. Handbook of the Austroasiatic Languages. Leiden: Brill.

Jonsson, Hjorleifur, 2011. Ethnology and the issue of human diversity in Mainland Southeast Asia. In Enfield (ed.), pp. 109-122.

Jonsson, Hjorleifur, 2014. Slow Anthropology: Negotiating Difference with the Iu Mien. Ithaca, NY: Cornell Southeast Asia Program Publications.

Konnerth, Linda, 2014. A Grammar of Karbi. Dissertation, University of Oregon, Eugene, OR.

Kosaka, Ryuichi, 2000. A Descriptive Study of the Lachi Language: Syntactic Description, Historical Reconstruction and Genetic Relation. Doctoral dissertation, Tokyo University of Foreign Studies, Tokyo.

Kölver, Ulrike, 1991. Local prepositions and serial verb constructions in Thai. In Hansjakob Seiler and Waldfried Premper (eds), Partizipation: Das sprachliche Erfassen von Sachverhalten, pp. 485-508. Tübingen: Narr.

Kruspe, Nicole, 2004. A Grammar of Semelai. Cambridge: Cambridge University Press.

Larish, Michael D., 2005. Moken and Moklen. In Nikolaus P. Himmelmann and Alexander Adelaar (eds), The Austronesian Languages of Asia and Madagascar, pp. 513-533. London: RoutledgeCurzon.

Lebar, Frank, Gerald Hickey and John Musgrave, 1964. Ethnic Groups of Mainland Southeast Asia. New Haven, CT: HRAF Press.

Li, Daqin, 2003. A Study of Geman. Beijing: The Nationalities Press. 
Li, Daqin, 2004. Sulong Yu Yan Jiu [A Study of Sulong]. Beijing: Minzu Chubanshe. Li, Yongsui, 2003. A Study of Sangkong. Beijing: The Nationalities Press.

Lidz, Liberty A., 2010. A Descriptive Grammar of Yongning Na (Mosuo). Doctoral dissertation, University of Texas at Austin.

Luong, H. V., 1988. Discursive practices and power structure: Person-referring forms and sociopolitical struggles in colonial Vietnam. American Ethnologist 15 (2): 239-253.

Luong, H. V., 1990. Discursive Practices and Linguistic Meanings: The Vietnamese System of Person Reference. Amsterdam: John Benjamins.

Majid, Asifa and Niclas Burenhult, 2014. Odors are expressible in language, as long as you speak the right language. Cognition 130 (2): 266-270.

Mao, Zongwu and Yunbing Li, 2002. A Study of Jiongnai. Beijing: Central Nationalities University Press.

Mao, Zongwu and Yunbing Li, 2007. Younuoyu Yanjiu [A Study of Younuo]. Beijing: Minzu University of China Publishing House.

Matisoff, James A., 1973. Tonogenesis in Southeast Asia. In Larry M. Hyman (ed.), Southern California Occasional Papers in Linguistics, no. 1, pp. 72-95. Los Angeles: University of Southern California.

Matisoff, James A., 1991. Areal and universal dimensions of grammatization in Lahu. In Elizabeth Closs Traugott and Bernd Heine (eds), Approaches to Grammaticalization, pp. 383-453. Amsterdam: John Benjamins.

Matisoff, James A., 2003a. Handbook of Proto-Tibeto-Burman. Berkeley, CA: University of California Press.

Matisoff, James A., 2003b. Aslian: Mon-Khmer of the Malay Peninsula. MonKhmer Studies 33: 1-58.

Matisoff, James A., 2015. Re-examining the genetic position of Jingpho: Putting flesh on the bones of the Jingpho/Luish relationship. In Enfield and Comrie (eds), pp. 109-150.

Mayuree, Thawornpat, 2006. Gong: An Endangered Language of Thailand. Doctoral dissertation, Mahidol University, Bangkok.

Michaud, Jean (ed.), 2010. Editorial: Zomia and beyond (Special Issue). Journal of Global History 5 (2): 187-214.

Morey, Stephen, 2005. The Tai Languages of Assam: A Grammar and Texts. Canberra: Pacific Linguistics.

Morey, Stephen, 2010. Turung: A Variety of Singpho Language Spoken in Assam. Canberra: Pacific Linguistics.

Morey, Stephen and Mark W. Post (eds), 2008. North East Indian Linguistics, vol. 1. New Delhi: Cambridge University Press India.

Morey, Stephen and Mark W. Post (eds), 2010. North East Indian Linguistics, vol. 2. New Delhi: Cambridge University Press India.

Muysken, Pieter (ed.), 2008. From Linguistic Areas to Areal Linguistics. Amsterdam: John Benjamins.

Nettle, Daniel, 1999. Linguistic Diversity. Oxford: Oxford University Press. 
Nichols, Johanna, 1992. Linguistic Diversity in Space and Time. Chicago: University of Chicago Press.

Nonaka, Angela M., 2004. The forgotten endangered languages: Lessons on the importance of remembering from Thailand's Ban Khor sign language. Language in Society 33 (5): 737-767.

O’Connor, Richard A., 1995. Agricultural change and ethnic succession in Southeast Asian states: A case for regional anthropology. The Journal of Asian Studies 54 (4): 968-996.

Oppenheimer, Stephen, 2011. MtDNA variation and southward Holocene human dispersals within Mainland Southeast Asia. In Enfield (ed.), pp. 81-108.

Oxenham, Marc and Nancy Tayles, 2006. Bioarchaeology of Southeast Asia. New York: Cambridge University Press.

Phattharathanit Srichomthong, 2012. Identity maintenance in Lanna (Northern Thai). Journal of the Southeast Asian Linguistics Society 5: 67-84.

Pittayaporn, Pittayawat, 2009. Proto-Southwestern-Thai: A new reconstruction. Journal of the Southeast Asian Linguistics Society 2: 119-143.

Pittayaporn, Pittayawat, 2015. Typologizing sesquisyllabicity: The role of structural analysis in the study of linguistic diversity in Mainland Southeast Asia. In Enfield and Comrie (eds), pp. 494-523.

Ploykaew, Pornsawan, 2001. Samre Grammar. Doctoral dissertation, Mahidol University, Bangkok.

Post, Mark W., 2007. A Grammar of Galo. Dissertation, La Trobe University, Melbourne.

Post, Mark W., 2011. Prosody and typological drift in Austroasiatic and Tibeto-Burman: Against 'Indosphere' and 'Sinosphere'. In S. Srichampa, Paul Sidwell and K. J. Gregerson (eds), Austroasiatic Studies: Papers from International Conference on Austroasiatic Linguistics (ICAAL4), pp. 198-211. Special issue of Mon-Khmer Studies 3. Canberra: Pacific Linguistics.

Post, Mark W. 2015. Morphosyntactic reconstruction in an arealhistorical context: A pre-historical relationship between North East India and Mainland Southeast Asia? In Enfield and Comrie (eds), pp. 205-261.

Ratliff, Martha, 2010. Hmong-Mien Language History. Studies in Language Change, vol. 8. Canberra: Pacific Linguistics.

Ratliff, Martha, 2015. Word-initial prenasalization in Southeast Asia: A historical perspective. In Enfield and Comrie (eds), pp. 29-48.

Sagart, Laurent, 2011. The Austroasiatics: East to west or west to east? In Enfield (ed.), pp. 345-359.

Sagart, Laurent, Roger Blench and A. Sanchez-Mazas (eds), 2005. The Peopling of East Asia: Putting Together Archaeology, Linguistics and Genetics. New York: RoutledgeCurzon.

Samarina, Irina, 2011. Jazyki gelao: Materialy k sopostavitel'nomu slovarju kadajskich jazykov [Gael Languages: Materials for a Comparative Dictionary of Kadai Languages]. Moskva: Academia. 
van Schendel, Willem, 2002. Geographies of knowing, geographies of ignorance: Jumping scale in Southeast Asia. Environment and Planning D: Society and Space 20 (6): 647-668.

Scott, James C., 2009. The Art of Not Being Governed: An Anarchist History of Upland Southeast Asia. New Haven, CT: Yale University Press.

Seng Mai, Ma, 2012. A Descriptive Grammar of Wa. MA thesis, Payap University, Chiang Mai, Thailand.

Shee, Naw Hsar, 2008. A Descriptive Grammar of Geba Karen. MA thesis, Payap University, Chiang Mai, Thailand.

Shintani, Tadahiko, 2008. The Palaung Language: the Comparative Lexicon of its Southern Dialects. Tokyo: Research Institute for Languages and Cultures of Asia and Africa (ILCCA).

Shorto, H. L., 1960. Word and syllable pattern in Palaung. Bulletin of the School of Oriental and African Studies 23 (3): 544-557.

Shorto, H. L., 2006. A Mon-Khmer Comparative Dictionary, edited by Paul Sidwell. Canberra: Pacific Linguistics.

Sidnell, Jack and Merav Shohet, 2013. The problem of peers in Vietnamese interaction. Journal of the Royal Anthropological Institute 19 (3): 618-638.

Sidwell, Paul, 2009. Proto-Mon-Khmer vocalism: Moving on from Shorto's 'alternances'. Journal of the Southeast Asian Linguistics Society 1: 205-214.

Sidwell, Paul, 2013. Southeast Asian Mainland: Linguistic history. In Peter Bellwood (ed.), The Encyclopedia of Global Human Migration, vol. 1: Prehistory, pp. 259-268. Oxford: Wiley-Blackwell.

Sidwell, Paul, 2015. Local drift and areal convergence in the restructuring of Mainland Southeast Asian languages. In Enfield and Comrie (eds), pp. 49-79.

Sidwell, Paul and Roger Blench, 2011. The Austroasiatic Urheimat: The southeastern riverine hypothesis. In Enfield (ed.), pp. 315-343.

Simpson, Andrew (ed.), 2007. Language and National Identity in Asia. Oxford: Oxford University Press.

Sophana Srichampa, 2008. Patterns of polite expressions in Vietnamese. The Mon-Khmer Studies Journal 38: 117-147.

de Sousa, Hilário, 2015. The Far Southern Sinitic languages as part of Mainland Southeast Asia. In Enfield and Comrie (eds), pp. 352-436.

Srisakorn, Preedaporn, 2008. So (Thavung) Grammar. Dissertation, Mahidol University, Bangkok.

Stolz, Thomas, 2002. No Sprachbund beyond this line! On the age-old discussion of how to define a linguistic area. In Paulo Ramat and Thomas Stolz (eds), Mediterranean Languages: Paper from the MEDTYP Workshop, Tirrenia, June 2000, pp. 259-281. Bochum: Brockmeyer.

Sun, Hongkai and Guangkun Liu, 2009. A Grammar of Anong: Language Death under Intense Contact, edited translation and annotation, with translation, editing, annotation and expansion by Graham Thurgood, Fengxiang Li and Ela Thurgood. Languages of the Greater Himalayan Region. Leiden: Brill. 
Suwilai Premsrirat, 1987. Khmu, a Minority Language of Thailand. Canberra: Pacific Linguistics.

Suwilai Premsrirat, 1998. Language maintenance and language shift in minority languages of Thailand. In Kazuto Matsumura (ed.), Studies in Endangered Languages, pp. 191-211. Tokyo: Hituzi Syobo.

Suwilai Premsrirat, 2007. Endangered languages of Thailand. International Journal of the Sociology of Language 186: 75-93.

Suwilai Premsrirat, 2008. Orthography development: A tool for revitalizing and maintaining ethnic minority languages. Journal of Language and Culture 26: 18-34.

Svantesson, Jan-Olof, Raw Kam, Kristina Lindell and Håkan Lundstrom, 2013. Dictionary of Kammu Yuan Language and Culture. Honolulu: University of Hawai'i Press.

Tarling, Nicholas, 1992. The Cambridge History of Southeast Asia: from Early Times to c. 1800, vol. 1. Cambridge University Press.

Thurgood, Graham, 1998. The development of the Chamic vowel system: the interaction of inheritance and borrowing. In David Thomas (ed.), Papers in Southeast Asian Linguistics, no. 15: Further Chamic Studies, pp. 61-90. Canberra: Pacific Linguistics.

Thurgood, Graham, 1999. From Ancient Cham to Modern Dialects: Two Thousand Years of Language Contact and Change. Honolulu: University of Hawai' $i$ Press.

Thurgood, Graham, 2010. Hainan Cham, Anong, and Eastern Cham: Three languages, three social contexts, three patterns of change. Journal of Language Contact, Varia 3: 39-61.

Thurgood, Graham and Randy J. La Polla, 2003. The Sino-Tibetan Languages. London: Routledge.

Thurgood, Graham, Ela Thurgood and Fengxiang Li, 2014. A Grammatical Sketch of Hainan Cham: History, Contact, and Phonology. Berlin: Mouton de Gruyter.

Tooley, M. J. and Ian Shennan (eds), 1987. Sea Level Changes. Oxford: Blackwell.

Umaporn, Sungkaman, 2007. Backchannel response in Mon conversation. Mon-Khmer Studies 37: 67-85.

Vittrant, Alice, 2015. Expressing motion: The contribution of Southeast Asian languages with reference to East Asian languages. In Enfield and Comrie (eds), pp. 579-625.

Vittrant, Alice and Justin Watkins (eds), in press. Languages of Mainland Southeast Asia Linguistic Area: Grammatical Sketches. Boston and Berlin: de Gruyter.

Voris, Harold K., 2000. Maps of Pleistocene sea levels in Southeast Asia: Shorelines, river systems and time durations. Journal of Biogeography 27 (5): 1153-1167.

Watkins, Justin, 2002. The Phonetics of Wa: Experimental Phonetics, Phonology, Orthography and Sociolinguistics. Canberra: Pacific Linguistics. 
Watkins, Justin (ed.), 2005. Studies in Burmese Linguistics. Canberra: Pacific Linguistics.

Watkins, Justin, 2013. Dictionary of Wa, two volumes. Leiden: Brill.

Wayesha, Ahsi James, 2010. A Phonological Description of Leinong Naga. MA thesis, Payap University, Chiang Mai, Thailand.

White, Joyce C., 2011. Cultural diversity in Mainland Southeast Asia: A view from prehistory. In Enfield (ed.), pp. 9-46.

Wnuk, Ewelina, 2016. Semantic Specificity of Perception Verbs in Maniq. Nijmegen: Radboud University.

Wnuk, Ewelina and Asifa Majid, 2014. Revisiting the limits of language: The odor lexicon of Maniq. Cognition 131 (1): 125-138.

Yip, Moira, 2002. Tone. Cambridge: Cambridge University Press.

Yu, Defen, 2007. Aspects of Lisu Phonology and Grammar, a Language of Southeast Asia. Canberra: Pacific Linguistics. 